\title{
The Influence of Positive Reinforcement on Employee Motivation at the Nakuru County Government
}

\author{
Daniel Kiptoo Maritim \\ Kabarak University
}

\begin{abstract}
Positive reinforcement is a motivational technique meant to elicit and to strengthen new behaviors by adding rewards and incentives instead of eliminating benefits. When used correctly, positive reinforcement can be very effective. This could go a long way to increase employee motivation and improve the public image of the organization. However, positive reinforcement has not yet been investigated as a employee motivator in the context of the nascent county governments in Kenya. As such the extent to which it is applied to influence employee motivation remains largely unknown. Therefore, this study sought to determine the influence of positive reinforcement on motivation of employees focusing on the Nakuru County Government. This study adopted the case study design targeting 80 Nakuru County Government management and staff members using simple random sampling. The questionnaires were used as instruments of data collection. Data was analyzed in using both descriptive and inferential statistical methods. The results revealed that positive reinforcement significantly $(r=0.404, p<0.05)$ promoted employee motivation at the Nakuru County Government. The findings underscored the importance of positive reinforcement on employee motivation. Therefore, it is recommended that positive reinforcement of employees needs to be encouraged in organizations especially in the public sector in Kenya where demand for improved service delivery is rising as citizens become more aware of their rights and entitlements.
\end{abstract}

Keywords: Positive Reinforcement, Employee Motivation, County Government

\section{Introduction}

It is evident that managers need to motivate employees to obtain the desirable results for the organization. There is consensus about the facts that motivation is an individual phenomenon. It is described as being intentional and multifaceted and that the purpose of motivational theories is to predict behavior. Irrespective of the industry within which an organization operates, the concept of motivation cannot be looked down upon (Jibowo, 2007). In this regard the public sector being service oriented and, therefore, having direct contact with the clients, the presence or absence of employees' motivation can have immediate telling effect on the customer-thus either delighting the customer or otherwise-which eventually results in increased public confidence in the public sector (Hassan, 2009). It is one of the driving forces that have direct impact on employee productivity. The critical workforce management challenges of the immediate future driven by corporate re-engineering and restructuring efforts, loyalty concerns and fierce competition for key talents are closely linked to the emerging issues of employees' commitment and productivity (Mondy, 2008).

According to Catania (2001), positive reinforcement is a motivational technique meant to elicit and to strengthen new behaviors by adding rewards and incentives instead of eliminating benefits. This technique can be applied in workplace through provision of fringe benefits, promotion opportunities and pay. According to Gohari, Ahmadloo, Boroujeni and Hosseinipour (2013) rewards can be classified into two categories which are intrinsic and extrinsic. Intrinsic reward refers to something intangible such as praise and acknowledgement while extrinsic reward is salary, promotion, freedom in office and job security. Both types of rewards are closely associated with staffs' accomplishments within an organization (Zani, Rahim, Junos, Samanol \& Ahmad, 2011). In operant conditioning, positive reinforcement involves the addition of a reinforcing stimulus following a behavior that makes it more likely that the behavior will occur again in the future. When a favorable outcome, event, or reward occurs after an action, then that particular response or behavior will be strengthened (Hall, 2013). The use of this theory in influencing behavior was advanced by B. F. Skinner introduced the reinforcement theory, also known as learning theory. It refers to the stimuli used to produce desired behaviors with different occurrences and schedules (Skinner, 1963). Motivational theorists have since adopted it for employee motivation in the the workplace.

There are many different types of reinforcers that can be used to increase behaviors, but it is important to note that the type of reinforcer used depends upon the individual and the situation (Schultz \& Schultz, 2010). While gold stars and tokens might be very effective reinforcement for a second-grader, they are not going to have the same effect with a high school or college student. Natural reinforcers are those that occur directly as a result of the behavior (White \& Gottfried, 2011). For example, a girl studies hard, pays attention in class, and does her homework. As a result, she gets excellent grades. Token reinforcers are points or tokens that are 
awarded for performing certain actions. These tokens can then be exchanged for something of value. Social reinforcers involve expressing approval of a behavior, such as a teacher, parent, or employer saying or writing "Good job" or "Excellent work." Tangible reinforcers involve the presentation of an actual, physical reward such as candy, treats, toys, money, and other desired objects. While these types of rewards can be powerfully motivating, they should be used sparingly and with caution.

When used correctly, positive reinforcement can be very effective. According to a behavioral guidelines checklist published by Utah State University, positive reinforcement is most effective when it occurs immediately after the behavior. The guidelines also recommend the reinforcement should be presented enthusiastically and should occur frequently. The shorter the amount of time between a behavior and the presentation of positive reinforcement, the stronger the connection will be. If a long period of time elapses between the behavior and the reinforcement, the weaker the connection will be. It also becomes more likely that an intervening behavior might accidentally be reinforced. In addition to the type of reinforcement used, the presentation schedule can also play a role in the strength of the response.

In the recent past Nakuru County Government faced performance issues. The employees joined forces with the members of county assembly in calling for the Governor's resignation. This shows dissatisfaction on the part of employees towards the management. Such management problems can be solved if good performance programs are initiated and employees motivated appropriately. When employees are properly motivated, the rate of labor turnover and absenteeism will be low; there will be good human relations in the organization as friction among the employees themselves and between employees and management will decrease (Battaglio \& Condrey, 2009); the number of complaints and grievances will come down (Hassan, 2009); there will be increase in the quantity and quality of product; wastage and scrap will be less, and the quality of products will improve which will also increase the public image of the organization (Shahid, 2009). However, positive reinforcement has not yet been investigated as a employee motivator in the county government. As such the extent to which it is applied to influence employee motivation remains largely unknown. It is in light of this that the research sought to investigate the influence of positive reinforcement on motivation of employees at the Nakuru County Government.

\section{Research Design and Methodology}

This research adopted the case study design targeting 92 management and staff members at the Nakuru County Government that were drawn using simple random sampling. The questionnaires were used as instruments of data collection. Data was analyzed in using both descriptive and inferential statistical methods. Inferential statistics involving correlations and regression analysis were done to determine the relationship between the dependent variable (motivation) and the independent variables.

\section{Results and Discussions}

This section presents results arising from the analysis of data collected using questionnaires. The study sought to establish the influence of positive reinforcement on employee motivation at the Nakuru County Government. The results are summarized in Table 1 and discussed as follows;

Table 1: Positive Reinforcement and Employee Motivation

\begin{tabular}{|l|l|l|l|l|l|l|l|}
\hline & SA & A & N & D & SD & & \multicolumn{1}{|l|}{} \\
\hline Positive Reinforcement & Freq(\%) & Freq(\%) & Freq $(\%)$ & Freq(\%) & Freq(\%) & $\chi 2$ & P-value \\
\hline Increased authority & $10(12.5)$ & $17(21.3)$ & $9(11.3)$ & $43(53.8)$ & $1(1.3)$ & 104.983 & 0.000 \\
\hline Monetary reward for job well done & $4(5.0)$ & $32(50.0)$ & $6(7.5)$ & $38(37.5)$ & 0 & 92.412 & 0.002 \\
\hline Increased responsibilities & $2(2.5)$ & $44(55.0)$ & $2(2.5)$ & $32(40.0)$ & 0 & 86.307 & 0.006 \\
\hline Non- monetary rewards & $7(8.8)$ & $42(52.5)$ & $9(11.3)$ & $22(27.5)$ & 0 & 103.838 & 0.000 \\
\hline Supervisory support & $2(2.5)$ & $39(48.8)$ & $4(5.0)$ & $32(40.0)$ & $3(3.8)$ & 109.239 & 0.000 \\
\hline
\end{tabular}

The results in Table 1 evidently suggest that increased authority was not used extensively as a means of positive reinforcement $(55.1 \%)$ among the employees. This means that as a result of the employees performance, they were not necessarily given more authority in their work areas. However, monetary rewards were given for jobs well done (55\%). For most $(57.5 \%)$ respondents, increased responsibilities and nonmonetary rewards $(61.3 \%)$ were used to reinforce their commitment to purpose in the institution. Supervisory support $(51.3 \%)$ was also used as a means of positive reinforcement. Hence, it can be deduced that the institution used a combination of intrinsic and extrinsic rewards to motivate the employees although most of the focus was on intrinsic rewards.

\section{Correlation Analysis}

These results of the correlation analyses are presented in Table 2 
Table 2 Summary of Correlations

\begin{tabular}{|l|l|l|l|}
\hline & Positive Reinforcement & $\begin{array}{c}\text { Motivation by the Nakuru } \\
\text { County Government }\end{array}$ \\
\hline Positive Reinforcement & $\begin{array}{c}\text { Pearson } \\
\text { Correlation }\end{array}$ & 1 & 0.404 \\
\hline & Sig. (2-tailed) & & 0.017 \\
\hline & $\mathrm{N}$ & 80 & 80 \\
\hline $\begin{array}{c}\text { Motivation by the Nakuru } \\
\text { County Government }\end{array}$ & $\begin{array}{c}\text { Pearson } \\
\text { Correlation }\end{array}$ & 0.404 & 1 \\
\hline & Sig. (2-tailed) & 0.017 & 80 \\
\hline & $\mathrm{N}$ & 80 & \\
\hline
\end{tabular}

The first correlation was done to determine whether positive reinforcement significantly promoted employee motivation at the Nakuru County Government shows that it was indeed significant $(r=0.404, p<$ 0.05). The Pearson's product moment coefficient of correlation $r=0.504$ is high suggesting that positive reinforcement strongly promoted employee motivation at the Nakuru County Government.

Table 3 Regression Analysis

\begin{tabular}{|l|l|l|l|l|}
\hline Model & R & R Square & Adjusted R Square & Std. Error of the Estimate \\
\hline 1 & $.404^{\mathrm{a}}$ & 0.1632 & 0.03 & 3.873 \\
\hline Model & & Unstandardized Coefficients & & Standardized Coefficients \\
\hline & & $\mathrm{B}$ & Std. Error & Beta \\
\hline 1 & (Constant) & 14.314 & 1.346 & \\
\hline & Positive Reinforcement & 0.148 & 0.08 & 0.206 \\
\hline
\end{tabular}

a. Dependent Variable: Motivation by the Nakuru County Government

The results in Table 3 show that the value obtained for $\mathrm{R}$, which is the model correlation coefficient was $r=0.404$ which was higher than any zero order value in the table. This indicates that the model improved when more variables were incorporated when trying to analyze the effects of motivation on employee performance at the Nakuru County government. The $r$ square value of, $r=0.1632$, also indicates that the multiple linear regression model could explain for approximately $16.3 \%$ of the variations in employee motivation in Nakuru County government while other variables not investigated in the present study could explain upto $83.7 \%$ of the variations in employee motivation not shown in the model. Moreover, the findings also suggest a linear relationship exists between the two variables. This led to the rejection of the null hypothesis $\mathrm{HO}_{1}$ : Positive reinforcement does not significantly influence employee motivation at the Nakuru County Government. The findings generally imply that the employees responded well to positive reinforcement at their workplace and it must, therefore, be taken into account when contemplating motivational strategies in an organization.

\section{Discussions}

The results on the influence of positive reinforcement on employee motivation at the county government reveal that it was the most significant factor of motivation. This meant that the members of the organization found it relatively easy to subscribe to it as compared to other forms of motivation. It was evident, though, that the institution used a combination of intrinsic and extrinsic rewards to motivate the employees although most of the focus was on intrinsic rewards. These results agree with Catania (2001) who opined that positive reinforcement is a motivational technique meant to elicit and to strengthen new behaviors by adding rewards and incentives instead of eliminating benefits. According to Hall (2013), when a favorable outcome, event, or reward occurs after an action, then that particular response or behavior will be strengthened. Gohari et al., (2013) further classified rewards into two categories which are intrinsic and extrinsic. Intrinsic reward refers to something intangible such as praise and acknowledgement while extrinsic reward is salary, promotion, freedom in office and job security.

\section{Conclusions and Recommendations}

The foregoing findings and discussions have underscored the importance of positive reinforcement on employee motivation. It borrows largely from the reinforcement theory and thus, it is intentionally meant to strengthen desireable attributes among employees in theorganization both through the application of intrinsic and extrinsic rewards. Positive reinforcement of employees needs to be encouraged in organizations especially in the public sector in Kenya where demand for improved service delivery is rising as citizens become more aware of their rights and entitlements. It is also recommended that the county government managements should 
be more consultative when engaging the staff in order to make them more confident in their work and foster good relations with the management and each other.

\section{References}

[1] Battaglio, D. \& Condrey, E. (2009). Reforming public management: Analyzing the impact of public Service reform on organizational and managerial trust. Journal of Public Administration Research and Theory 19: 689-707.

[2] Catania, A. (2001), "Positive Psychology and Positive Reinforcement," American Psychologist, 56(1), 86-87.

[3] Gohari, P. Ahmadloo, A. Boroujeni, B. \& Hosseinipour, J. (2013) "The Relationship between Rewards and Employee Performance," Interdisciplinary Journal of Contemporary Research in Business, 5(3): 543-570.

[4] Hall, P. S. (2013), "A New Definition of Punishment," Reclaiming Children and Youth, 21(4) 22-26.

[5] Hassan, S., (2009). The role of psychological climate on public sector employees' affective commitment: An empirical assessment for three occupational groups. International Public Management Journal Jibowo, A.(2007). Effect of Motivators and hygiene factors on job performance among extension workers in the former Western state of Nigeria. The quarterly journal of Administration. 4 (3):19-20

[6] Mondy R (2008). Human Resource Management. 10th ed., New Jersey: Prentice-Hall.

[7] Pearce, L., Stevenson, B., \& Perry, J. L. (1985). Managerial Compensation Based on Organizational Performance: A Time Series Analysis of the Eff ects of Merit Pay. Academy of Management Journal, 28 (2): 261- 78.

[8] Schultz, L. \& Schultz, D.(2010). Psychology and work today. New York: Prentice Hall. pp. 38-39(10th ed. ed). Skinner, F. (1963) “Operant Behaviour," American Psychologist, 18(8) 503-515.

[9] White, M. \& Gottfried, J. (2011). "Reward: What Is It? How Can It Be Inferred from Behavior?". PMID 22593908.

[10] Zani, R., Rahim, N., Junos, S., Samanol S. \& Ahmad, S. (2011), "Comparing the Impact of Financial and Non- Financial Rewards towards Organizational Motivation,” Interdisciplinary Journal of Contemporary Research in Business,3(4): 328-334. 